\title{
Hyperthermia, radiation and chemotherapy: the role of heat in multidisciplinary cancer care.
}

\author{
Mark Hurwitz, MD \\ Thomas Jefferson University and Hospitals \\ Paul R. Stauffer \\ Thomas Jefferson University
}

Follow this and additional works at: https://jdc.jefferson.edu/radoncfp

Part of the Oncology Commons, and the Radiology Commons

Let us know how access to this document benefits you

\section{Recommended Citation}

Hurwitz, MD, Mark and Stauffer, Paul R., "Hyperthermia, radiation and chemotherapy: the role of heat in multidisciplinary cancer care." (2014). Department of Radiation Oncology Faculty Papers. Paper 69.

https://jdc.jefferson.edu/radoncfp/69

This Article is brought to you for free and open access by the Jefferson Digital Commons. The Jefferson Digital Commons is a service of Thomas Jefferson University's Center for Teaching and Learning (CTL). The Commons is a showcase for Jefferson books and journals, peer-reviewed scholarly publications, unique historical collections from the University archives, and teaching tools. The Jefferson Digital Commons allows researchers and interested readers anywhere in the world to learn about and keep up to date with Jefferson scholarship. This article has been accepted for inclusion in Department of Radiation Oncology Faculty Papers by an authorized administrator of the Jefferson Digital Commons. For more information, please contact: JeffersonDigitalCommons@jefferson.edu. 


\section{HYPERTHERMIA, RADIATION AND CHEMOTHERAPY:}

\section{THE ROLE OF HEAT IN MULTIDISCIPLINARY CANCER CARE}

\section{MARK HURWITZ M.D.}

PAUL STAUFFER MS, MSEE

\section{HISTORICAL BACKGROUND}

The therapeutic potential of heat has been recognized for nearly 5000 years. The first recorded use of medicinal heat dates back to the $27^{\text {th }}$ century B.C. in Egypt where direct application of hot blades or sticks were used to ablate breast cancer. ${ }^{(1)}$ There are reports of various therapeutic uses of heat in ancient China and India as well. ${ }^{(2)}$ The ancient Greeks recognized the therapeutic value of moderate temperature elevations such as occurs with fever. In the $6^{\text {th }}$ Century B.C. Paramenides stated "Give me the power to produce fever and I will cure all diseases". ${ }^{(3)}$ Subsequently Hippocrates applied hyperthermia to treat breast cancer. He expressed admiration for the therapeutic benefit of heat stating; "That which drugs fail to cure, the scalpel can cure. That which the scalpel fails to cure, heat can cure. If heat cannot cure, it must be deemed incurable." ${ }^{\prime(4)}$ Over the ensuing several centuries there is documented use of moderate heating to cure a variety of diseases in Greece and subsequently the Roman Empire. ${ }^{(5)}$

In the $19^{\text {th }}$ Century Busch reported successful use of infection to treat cancer and in 1893 Coley retrospectively reviewed the cases of 38 patients with advanced cancer who developed high fevers spontaneously or after purposeful infection with erysipelas. Thirty one of these patients experienced a remission in their cancers including twelve with a complete clinical response. ${ }^{(6)}$ 
The first report of use of radiation with hyperthermia is a German phase II trial published in 1910. One hundred patients with a variety of pathologically confirmed advanced cancer were treated with radiation and diathermy, a technique for local heating of body tissues with electric currents. Thirty two patients experienced complete regression while another 32 experienced temporary improvement. ${ }^{(7)}$ In 1935 Warren reported on combined induced fever with roentgen therapy which resulted in significant improvement and palliation in 29 of 32 end stage oncology patients. ${ }^{(8)}$

\section{THERMAL BIOLOGY}

\section{Biologic Rationale For Combining Heat With Radiation and Chemotherapy}

The biologic basis for benefit of hyperthermia with modern cancer therapies including radiation and chemotherapy began to be appreciated by the 1970's. In regards to radiation therapy, hyperthermia was recognized as an ideal complementary treatment. Many conditions that contribute to radioresistance including hypoxia, acidification, and S-phase of the cell cycle either enhance sensitivity to heat or do not temper it. ${ }^{(9-15)}$ (FIGURE 1) Hyperthermia also typically results in enhanced perfusion that may result in improved tumor oxygenation for subsequent radiation treatments. ${ }^{(16-17)}$

Chemosensitization with hyperthermia is dependent on the particular mechanism of effect for each agent. The magnitude of effect ranges from none as is typical with anti-metabolites to synergistic effects such as with cisplatin. (FIGURE 2) The mechanism of enhanced cytotoxicity can include increased intracellular drug accumulation, inhibition of DNA repair, abrogation of cell cycling in S-phase when cells

are most sensitive to heat, enhanced free radical production, and reversal of drug resistance. ${ }^{(18-20))}$ Drugs for which synergistic effects have been noted include cisplatin, adriamycin, bleomycin, melphalan, cyclophosphamide, nitrosoureas, nitrogen mustards, and mitomycin c. ${ }^{(19)}$ Interaction of hyperthermia with other agents including taxanes and anti-metabolites is possible although for many agents the complex interactions that contribute to enhanced treatment effects 
remain to be fully defined. ${ }^{(20)}$ In regards to timing and sequencing, simultaneous administration or chemotherapy followed immediately by hyperthermia has been shown to have the greatest effects.

\section{Mechanism of Cell Death With Hyperthermia}

High temperatures achieved with thermal ablation, typically in the range of $65-85^{\circ} \mathrm{C}$ result in instantaneous cell death. Temperatures above $45^{\circ} \mathrm{C}$ sustained for sufficient time will lead to protein denaturization and cell death typically via necrosis. Clinical hyperthermia involves temperature elevations in the range of $39-45^{\circ} \mathrm{C}$ Within this moderate temperature elevation range, tumor cell death occurs in a log-linear manner with an initial shoulder region followed by a steeper decline in cell survival correlated with increasing temperatures up to $45^{\circ} \mathrm{C}$. While temperatures between $42-45^{\circ} \mathrm{C}$ can result in cell death with sufficiently long exposure, use of hyperthermia alone is not a practical nor particularly effective theraupeutic strategy as monotherapy. The primary benefit of hyperthermia with moderate temperature elevation is therefore achieved through enhancement of anti-tumor effects through combination with either radiation or chemotherapy.

The precise mechanisms by which moderate temperature hyperthermia results in tumor cell death are complex and highly dependent on the heating profile. In addition to complementary biologic effects with radiation and chemotherapy, mechanisms for direct effect include protein denaturization including inhibition of sub-lethal and potentially lethal damage repair through inactivation of DNA repair pathways leading to mitotic catastrophe, induction of senescence, apoptosis, and necrosis. ${ }^{\text {(21-28) }}$ Research has revealed that protein denaturization is a key biologic effect of hyperthermia at modest temperature elevations. ${ }^{(29)}$ The activation energeries for protein denaturization and heat induced cell death were noted to be within the same range. Further research suggested that nuclear proteins are most sensitive ${ }^{(30-32)}$ and a high degree of correlation of nuclear protein aggregation and heat induced cell kill has been noted. Radiation sensitization is achieved in large part through nuclear protein aggregation which inhibits the DNA repair process thus converting potentially lethal radiation induced DNA breaks into lethal events. Specifically, heat induces changes in DNA repair foci such as the MRN complex which 
includes MRE11, rad 50, and nbs1, key proteins involved in double strand break repair, the nucleolus and on the complexes that anchor DNA to the nuclear matrix thus contributing to radiosensitization. ${ }^{(33-34)}$ Chromosomal aberrations may also occur due to heat sensitivity of the centriole. ${ }^{(35)}$ Failure of DNA replication in S-Phase of the cell cycle results in mitotic catastrophe. Research to date has made it clear however that other mechanisms including necrosis, apoptosis and senescence also have important roles in hyperthermic cell kill. Temperatures above $44-45^{\circ} \mathrm{C}$ generally lead to cell death via extensive protein denaturization and necrosis. ${ }^{(36) .}$ Apoptosis has been noted at more moderate temperature elevations such at $41.5^{\circ} \mathrm{C}$ sustained for one to two hours. ${ }^{(37)}$ Stress induced premature senescence may also occur in response to heat shock. ${ }^{(38)}$

\section{Heat Shock Proteins}

Heat shock proteins (HSP) play a central role in hyperthermia response. Heat shock proteins (HSP), first identified in relation to thermal stress are now recognized as ubiquitous proteins involved in general cellular stress response and also for their role in immune modulation. HSP were discovered in 1961 by 
Chanel and Maury who described the effects of thermal shock on blood proteins in fish. ${ }^{(39)}$ While initially identified in relation to heat shock and thus named as such, HSP are now known to have a universal role in cellular stress response. In the intracellular milieu HSPs have a primary role in stabilizing damaged proteins allowing for repair. This protective mechanism however has negative connotations for treatments directed at killing cancer cells. This response which may last for several days has potential to abrogate the effects of hyperthermia. This concept is referred to as thermal tolerance. The induction of thermal tolerance has been found to be associated with HSP up regulation. ${ }^{(40-41)}$ Due to concerns about thermal tolerance, hyperthermia is typically delivered no more than a few times per week, generally with at least 72 hours between treatments.

While serving a protective role for the cancer cell in the intracellular environment, HSP have potentially beneficial anti-neoplastic effects in the extracellular milieu. HSPs have chaperokine effects which include a central role in cellular immune regulation coupled with the ability to stimulate proinflammatory cytokine production. ${ }^{(42)}$ HSP-PC complexes with functional CD8+ cells and macrophages are all required for induction of immunity. ${ }^{(43)}$ The chaperone function of HSP relates to their role in shuttling immunogenic peptides onto MHCs for presentation to T cells. Notably, HSP-PC complexes can induce tumor-specific immunity. ${ }^{(44-46)}$ (FIGURE 3)

Radiation has also been shown to have similar effects in regard to immune response. In the clinical setting, a consistent increase in serum HSP70 over the duration of a standardly fractionated course of radiation therapy for prostate cancer patients was noted. This increase in HSP70 was associated as expected with increase in proinflammatory cytokines and components of the cellular immune response including CD8+ and natural killer cells. Cell and animal modeling indicated this response is consistent with tumor specificity. ${ }^{(47)}$ Optimization of immune response with combination of hyperthermia with 
radiation and the ever increasing number of immunotherapeutics remains an active area of emerging investigation.

\section{Thermal Enhancement Ratio}

The additional anti-neoplastic effect achieved with hyperthermia is referred to as the thermal enhancement ratio or TER. TER is the ratio of radiation or chemotherapy doses required to produce a given level of biological damage with versus without heat. The finding of a significant TER as first defined in the laboratory has subsequently been demonstrated in clinical practice with most studies indicating a TER of approximately 1.5. (FIGURE 4)

\section{THERMAL PHYSICS}

\section{Mechanisms of Heating}

While there are hundreds of medical devices available to administer thermal therapy, there are just three basic mechanisms of heat delivery to tissue: thermal conduction, resistive or dielectric losses, and mechanical losses from molecular collisions. The most fundamental mechanism of heat transfer in the body is thermal conduction, which causes a net flow of heat energy from higher to lower temperature at a rate dependent on the tissue thermal properties and temperature gradient.

Resistive or dielectric losses result from an applied electromagnetic (EM) field. Critical factors in selecting appropriate EM frequency are tumor size and depth. Dielectric losses increase with frequency, increasingly restricting tissue penetration at microwave frequencies greater than $150 \mathrm{MHz}$. Spatial resolution (focal spot size) is approximately one half the wavelength in tissue which varies from a tumorsized $4 \mathrm{~cm}$ at $1000 \mathrm{MHz}$ to $>3 \mathrm{~m}$ at radiofrequencies (RF) below $100 \mathrm{MHz}$. Therefore a tradeoff exists between RF sources that can penetrate deep in the body but cannot selectively heat small volumes 
versus microwave sources that can focus energy into smaller tumors but cannot penetrate deep below the surface.

The third mechanism of heat generation involves mechanical losses from molecular collisions as induced by an ultrasound (US) pressure wave. Like EM energy, US attenuates exponentially with depth in soft tissue. Furthermore, ultrasound absorption is fifty times greater in bone than soft tissue and therefore cannot be applied when there is bone between the applicator and the target. The most useful frequencies for power deposition in human anatomy are in the range of $0.5-10 \mathrm{MHz}$ which have wavelengths ranging from $0.1-3 \mathrm{~mm}$. These wavelengths are much shorter than the tumor dimensions and allow a focal spot size less than $2 \mathrm{~mm}$ diameter. Due to lower attenuation rate in soft tissue, US can penetrate deeper than EM energy.

\section{Approaches To Heating}

Heating approaches include whole body, deep-regional, deep-focused, superficial, or interstitial/intracavitary techniques. (FIGURE 5)

\section{Whole Body Heating}

Regardless of tumor location within the body, the most uniform tumor temperatures are possible by heating the entire body. The disadvantages are systemic stress and a limitation to $<42^{\circ} \mathrm{C}$ due to thermosensitivity of critical tissues like heart, liver and brain. Thus the thermal goals of systemic therapy are usually more modest than local heating techniques, and intended for activation of drugs ${ }^{(48)}$ or enhancement of immunologic response ${ }^{(49-50))}$ rather than radiosensitization. When heating the whole body, normal body-cooling mechanisms such as respiration and skin cooling must be blocked by thermally insulating the patient and preheating the breathing circuit. The patient is often anesthetized or sedated and physiologic conditions and electrolyte balance must be carefully controlled throughout 
treatment which generally lasts many hours. Following early work using induced fever therapy, ${ }^{(51)}$ systemic heating is generally accomplished via thermal conduction heating from immersion in heated fluid or air. ${ }^{(52-55)}$ The heating process can be accelerated using infrared radiation. ${ }^{(56)}$ For some applications, regional heating is sufficient with invasive approaches like intraperitoneal irrigation ${ }^{(57)}$ or circulating blood that is heated by exteriorized arterio-venus shunts through organs ${ }^{(58)}$ or limbs ${ }^{(59)}$.

\section{Isolated Limb and Peritoneal Perfusion}

Hyperthermic limb perfusion involves isolating the limb from systemic circulation, typically with a tourniquet, after which chemotherapy is administered, often in the range of 60 minutes with

extracorporeal circulation. ${ }^{(60-61)}$ At the beginning of perfusion phase, the blood of the limb is heated after which chemotherapy infusion begins. Therefore a high concentration of chemotherapy can be delivered to the targeted limb while minimizing systemic toxicity. With peritoneal infusion the chemotherapeutic agent is heated and then injected directly into the targeted region. ${ }^{(62-64)}$

\section{Deep Regional Heating}

Deep penetration of heat is best accomplished with array applicators that spread out superficial power deposition across a large surface area and combine geometrically to produce a concentrated heat focus at depth. The most practical approach to heat large tumor volumes at depth is the use of electromagnetic fields in the range of $8-140 \mathrm{MHz}$. This approach takes advantage of wavelengths that are long compared to body dimensions and thus deposit energy deeper and over a sizeable region.

\section{Deep Focused Heating}

Deep focused techniques include interstitial implantation of heatable sources into the body and more recently injectable paramagnetic nanofluids. Alternative magnetic fields (AMF) can be used to heat ferromagnetic seeds of fluids implanted in the body. These strategies have been investigated for 
prostate cancer where placement of the heatable seeds is similar in technique to implantation of radioactive seeds as done for prostate brachytherapy. ${ }^{(65-66)}$

\section{Superficial Heating}

To date, microwave applicators are used most frequently for heating superficial tissue disease less than $3 \mathrm{~cm}$ deep. In the US, the most common device is the microwave waveguide, a simple rectangular or circular metal structure that guides EM waves from a single monopole feed out the open aperture which is at least a half wavelength in largest dimension. Waveguide antennas are commercially available from 7.5 to $24 \mathrm{~cm}$, designed for use at approved Industrial Scientific and Medical (ISM) band frequencies of 915 or $2450 \mathrm{MHz}$ in the US, ${ }^{(67-70)}$ or $430-434 \mathrm{MHz}$ in Europe ${ }^{(71-72)}$ and Asia. ${ }^{(73-74)}$

\section{CLINICAL HYPERTHERMIA}

\section{Early Clinical Experience}

Enthusiasm quickly waxed in the 1970's and 1980's for hyperthermia with realization of the potential for therapeutic gain combining moderate temperate heating and radiation. The Radiation Therapy Oncology Group initiated two phase III trials in the 1980s. These trials however were hampered by several key limitations including the inability at that time to effectively heat many tumors with the technology available, lack of appreciation for meaningful goals in prescribing hyperthermia, and lack of quality assurance guidelines.

RTOG 81-04 compared radiation with or without hyperthermia for a variety of malignancies including breast, head and neck, trunk, and extremity tumors. No difference was noted in complete response between groups; however, benefit was noted for tumors less than $3 \mathrm{~cm}$, suggesting that if tumors could be effectively heated meaningful clinical responses could be achieved. ${ }^{(75)}$ A second phase II trial, RTOG 84-19 was conducted to assess use of radiation with or without interstitial hyperthermia for persistent 
or recurrent tumors after previous radiation or surgery. No difference in any of the study endpoints was noted; however, only 1 of 173 evaluable patients met the minimum accepted criteria for adequate hyperthermia. The authors concluded that the study ultimately failed in its objective to assess the value

of hyperthermia. ${ }^{(76)}$ Coupled with other challenges including the typical hour or more needed to administer hyperthermia, the difficulties in administering hyperthermia and lack of standards led many radiation oncologists to abandon pursuit of hyperthermia.

\section{Additional Randomized Trials}

Following the RTOG trial experience, over 20 randomized trials assessing hyperthermia with radiation or chemotherapy have been published with most demonstrating benefit to the addition of hyperthermia. These studies, while often of modest size, have shown benefit for hyperthermia in treatment of a wide range of malignancies including glioblastoma multiforme, head and neck cancer, breast cancer, melanoma, esophageal malignancies, and sarcoma.

\section{Randomized Trials of Hyperthermia and Radiation CNS Malignancies}

Hyperthermia has been shown to benefit patients with glioblastoma multiforme (GBM). Researchers at the University of California at San Francisco randomized 79 patients following surgery and standard external beam radiation therapy to $59.4 \mathrm{~Gy}$ to undergo an interstitial brachytherapy boost of 60 Gy with or without interstitial hyperthermia. Time to progression and overall survival was significantly increased with the addition of hyperthermia. Two year overall survival was $31 \%$ vs $15 \%$ with vs without hyperthermia. A multivariate analysis adjusting for age and KPS showed that improved survival was significantly associated with randomization to "heat" with a hazard ration of $0.51 .{ }^{(77)}$

\section{Head and Neck Cancer}


In regard to head and neck cancers, two small randomized trials have revealed benefit to addition of hyperthermia to radiation in treatment. In one study pre-dating routine use of chemotherapy in locally advanced head and neck cancer, 65 patients were randomized to radiation alone vs. radiotherapy and hyperthermia. Radiation included $50 \mathrm{~Gy}$ in five weeks to the primary site and regional lymphatics followed by a boost of 10 to $15 \mathrm{~Gy}$ to the site of gross disease. Hyperthermia was administered twice weekly. Response as expected was excellent in either arm for patients with early stage disease with 12 of 13 experiencing complete response. For patients with stage III or IV disease complete response was increased from $20 \%$ and $7 \%$ with radiation therapy alone to $58 \%$ and $38 \%$ respectively with addition of hyperthermia. While the radiation therapy and lack of use of chemotherapy as applied for these patients treated in the 1980s can be rightly cited as inferior by current standards, the results are instructive in demonstrating the ability of hyperthermia to enhance radiotherapeutic outcomes. ${ }^{(78)}$

A phase III trial in Italy from this era assessed the impact of hyperthermia when applied with radiation in treatment of N3 squamous cell cervical lymph nodes. The primary endpoints were local control at 3 months and acute local toxicity. A planned interim analysis inclusive of 41 patients revealed a statistically significant difference in complete response rates in lymph nodes treated with hyperthermia. The complete response rate in the combined arm was $82.3 \%$ compared to $36.8 \%$ with radiation alone. In light of these very positive results the study was closed to further accrual. Treatment was also noted to be well tolerated. Apart from skin burns generally mild in severity, acute local toxicities were similar in both groups. One patient in the combined heat and radiotherapy arm died two months after completion of therapy with a carotid rupture which may have been associated with extensive tumor necrosis. A longer term analysis reported actuarial 5 year overall survival of $55 \%$ vs. $0 \%$ in the hyperthermia vs. radiation alone arms. ${ }^{(79)}$

In a more recent study from India, 56 patients were randomized to receive radiation alone or with hyperthermia for treatment of tumors of the oropharynx, hypophaynx, or larynx. Over $90 \%$ had stage 3 or 4 
disease. A complete response was observed in $79 \%$ of patients randomized to hyperthermia as opposed to $42 \%$ of patients in the radiation alone arm. Survival was also significantly increased on the hyperthermia arm to 8.0 months as compared to 4.8 months with radiation alone. ${ }^{\left({ }^{80}\right)}$ Notably, chemotherapy and IMRT were not utilized, a significant number of patients in both arms did not complete the intended treatment or were lost to follow-up, and overall outcomes were worse than expected with optimal standard therapy, therefore limiting the conclusions that can be drawn from this study. Never-the-less overall these head and neck trials indicate there is significant potential for hyperthermia to improve outcomes for head and neck malignances. Thus additional study with present state-of-the-art radiation and chemotherapy is warranted.

\section{Lung Cancer}

Data in lung cancer is relatively limited given the challenges of safely heating lung without inducing thermal damage. An International Atomic Energy Agency (IAEA)-sponsored, multi-institutional prospective randomized trial was, however, successfully completed. This trial was designed to assess whether the combination of hyperthermia and radiation improves the local response rate of locally advanced non-small cell lung cancer (NSCLC) compared with radiation alone. 80 patients with locally advanced NSCLC were randomized. The primary endpoint was local response rate. Secondary endpoints included local progressionfree survival and overall survival. No significant differences between the two arms with regard to local response rate or overall survival rate was noted. However, local progression- free survival was significantly better with the addition of hyperthermia. Toxicity was generally mild and no grade 3 late toxicity was observed in either $\operatorname{arm} .^{(81)}$

\section{Breast Cancer}

Hyperthermia has been shown to improve complete response and local control for women with breast cancer, particularly in the setting of recurrent chest wall disease. Vernon reported combined 
results of five randomized breast cancer trials in Europe and North America including both locally advanced primary disease and recurrent disease for which radiation therapy was indicated and surgery contraindicated. ${ }^{(82)}$ Three distinct groups were studied: patients with inoperable primary disease, recurrent disease in un-irradiated sites, and recurrent disease in previously radiated areas. The primary endpoint in each trial was local tumor response.

A decision to perform a combined analysis was made after initiation of the individual studies due to slow accrual. A prospective statistical plan was generated to allow for assessment of the initial objectives. A total of 306 eligible patients were enrolled. Treated lesions included chest wall (71\%) and intact breast tissue (26\%). $48 \%$ of cases included multiple lesions. There were a greater number of patients who had received prior chemotherapy and lesion size was greater in the hyperthermia plus radiation treatment arm. A highly significant difference in complete response was note for combined radiation and hyperthermia, 59\%, vs. radiation alone, $41 \%$. On further analysis it was determined this difference was driven by benefit in patients undergoing re-irradiation for whom radiation doses were limited. In this group there was nearly a doubling of complete response with the addition of hyperthermia to radiation of $59 \%$ as compared to $31 \%$ with radiation alone. Patients achieving a complete response who received hyperthermia had a reduced risk of recurrence with hazard ratio of 0.67 compared to patients who received radiation alone. Treatment with hyperthermia was well tolerated. Apart from acute occurrence of skin blistering of $11 \%$ vs. $2 \%$ with vs. without hyperthermia no differences in either acute or late toxicity were noted.

Researchers at Duke University confirmed a dose response relationship for hyperthermia in a randomized trial in which patients with superficial tumors $\leq 3 \mathrm{~cm}$ depth received either "low" vs "high" dose hyperthermia combined with radiation. As prior studies had shown a thermal dose of $\mathrm{CEM} 43^{\circ} \mathrm{C} \mathrm{T}_{90}$ (the number of cumulative equivalent minutes at $43^{\circ} \mathrm{C}$ exceeded by $90 \%$ of monitored points within the tumor) 
equated with improved treatment outcome, ${ }^{(83-84)}$ hyperthermia was prescribed to either $\mathrm{CEM} 43^{\circ} \mathrm{C} \mathrm{T}_{90}<1$ or CEM $43^{\circ} \mathrm{C} \mathrm{T}_{90}>10.122$ patients were enrolled of which $89 \%$ were determined at the time of first hyperthermia treatment to have tumors that could be effectively heated. These 109 patients were randomized to receive either no further hyperthermia or twice weekly hyperthermia over their course of radiation therapy up to 10 treatments. Patients were also stratified by whether they had received prior radiation therapy and by site of disease. Median CEM $43^{\circ} \mathrm{C} \mathrm{T}_{90}$ in the low and high dose hyperthermia groups was 0.74 and 14.3 respectively. $65 \%$ of patients had breast or chest wall disease, $13 \%$ head and neck, $11 \%$ melanoma, with the remainder having various other malignancies, $36 \%$ of patients had received prior radiation. Median radiation dose was $41 \mathrm{~Gy}$ in previously treated patients and $60 \mathrm{~Gy}$ for those not previously irradiated.

Higher dose hyperthermia was found to be beneficial. Complete response rate in the high dose arm was $66 \%$ and in the low HT arm $42 \%$. The odds ratio for complete response was 2.7 . This improvement in complete response translated into improved duration of local control of $48 \%$ vs. $25 \%$ at the time of death or last followup. Previously irradiated patients had the greatest incremental gain in complete response, $23 \%$ in the no HT arm vs. $68 \%$ in the $\mathrm{HT}$ arm as compared to $51 \%$ vs. $65 \%$ for patients without prior radiation therapy. The toxicity profile was also excellent. The study therefore demonstrated that thermal dose can be prospectively prescribed and delivered, and correlates with outcome. ${ }^{(85)}$

\section{Pelvic Malignancies}

In a multicenter trial in the Netherlands patients with locally advanced pelvic tumors were randomized to radiation alone or radiation plus hyperthermia. 363 patients with bulky stage 1B or IIB-IVA cervical, T3 or T4 bladder or unresectable or recurrent rectal cancers were stratified based on primary disease site. With median 2 year follow-up local control with radiation and hyperthermia vs. radiation alone was $56 \%$ vs. $39 \%$. 3 year overall survival was significantly improved with the addition of hyperthermia, $31 \%$ vs. $24 \%$. On 
further analysis this benefit was determined to be due to a highly significant benefit for patients with cervical cancer with improvement in overall survival to $51 \%$ with hyperthermia compared with $27 \%$ for those receiving radiation alone. Apart from an $11 \%$ acute rate of skin burns which resolved with conservative treatment there were no significant differences in short or long-term toxicity. ${ }^{\left({ }^{6}\right)}$ Contemporaneous with publication of these impressive results, several studies were published showing a similar benefit to the addition of cisplatin to radiation in treatment of locally advanced cervical cancer established combined radiation and chemotherapy as standard of care. ${ }^{(87)}$ Two studies exploring potential additional benefit of hyperthermia to both radiation and chemotherapy were subsequently initiated but closed due to poor accrual leaving this questioned yet unanswered.

In 2010 a Cochrane review of 6 randomized controlled trials assessing radiation vs. radiation plus hyperthermia for locally advance cervical cancer found that addition of hyperthermia was associated with a significantly higher complete response rate with relative risk 0.56; a significantly reduced local recurrence rate with hazard ratio 0.48 ; and a significantly better overall survival following the combined treatment with HR 0.67. No increase in short or long-term toxicity was observed. The authors noted several limitations with the data including the limited number of patients available for analysis, methodological flaws and a significant over-representation of patients with FIGO stage IIIB (74\%) which prohibited drawing definite conclusions regarding the impact of adding hyperthermia to standard radiotherapy. They went on to note, however, available data does suggest that the addition of hyperthermia improves local tumor control and overall survival in patients with locally advanced cervix carcinoma without affecting treatment related grade 3 to 4 acute or late toxicity. ${ }^{(88)}$

Several randomized studies have assessed the role of the addition of hyperthermia to radiation in treatment of rectal cancer. Another Cochrane review identified six randomized controlled trials for rectal cancer published between 1990 and 2007 including 520 patients evenly divided between treatment arms. Four studies including a total of 424 patients reported overall survival rates. After 2 years, overall survival was significantly improved with 
the addition of hyperthermia with hazard ratio of 2.1 however this benefit disappeared with longer follow-up. Five of the studies reported complete response rates with significantly higher rate of complete response observed in the combined treatment group with relative risk of 2.8 . No significant differences were noted in acute toxicity in two studies reporting this outcome. Late toxicity was not assessed. While these finding were promising, the authors concluded that additional studies are needed to compare chemoradiation versus thermoradiation versus chemoradiation plus hyperthermia in high quality controlled randomized trials. ${ }^{(89)}$

\section{Skin Cancer}

Hyperthermia has also been demonstrated to be beneficial in treatment of melanoma. The European Society for Hyperthermic Oncology conducted a multi-center phase III trial involving 134 metastatic or recurrent lesions of malignant melanoma in 70 patients randomly assigned to receive radiotherapy with three fractions of 8 Gy or $9 \mathrm{~Gy}$ in 8 days alone or followed by hyperthermia. Addition of hyperthermia significantly increased local control from $28 \%$ to $46 \%$. The overall 5 -year survival rate was $19 \%$, however $38 \%$ of the patients for whom all known disease was controlled survived 5 years demonstrating the contribution of local control to survival. $^{(90)}$

\section{Randomized Trials of Chemotherapy and Hyperthermia Sarcoma}

The European Organization for the Research and Treatment of Cancer (EORTC) in cooperation with the European Society for Hyperthermic Oncology (ESHO) reported results of a phase III trial revealing benefit to addition of hyperthermia to chemotherapy for treatment of sarcoma. 341 patients with either primary or recurrent clinically localized high-risk soft-tissue sarcoma defined as $\geq 5 \mathrm{~cm}$ grade $2-3$, deep to the fascia were randomized to either chemotherapy alone or combined with regional hyperthermia in 
addition to local therapy. Chemotherapy consisted of 4 cycles of neoadjuvant etoposide, ifosfamide, and doxorubicin (EIA) followed by surgery and when indicated radiotherapy to 50-60 Gy with boost up to $66 \mathrm{~Gy}$ in standard fractionation followed by an additional 4 cycles of EIA. Patients randomized to hyperthermia received hyperthermia in combination with chemotherapy on days 1 and 4 of each 3 week chemotherapy cycle pre and post-surgery. Patient and tumor characteristics were evenly matched. Local progression free survival, the primary endpoint, was improved at 2 years with the addition of hyperthermia to $76 \%$ from $61 \%$ with chemotherapy alone. The hazard ration for local progression or death with hyperthermia was 0.58 . The relative hazard for disease free survival was also reduced with hyperthermia at 0.70 with median duration of 32 vs. 18 months with vs. without hyperthermia. In a pre-specified per protocol analysis comparing patients who completed EIA and hyperthermia vs. those who completed EIA alone revealed an overall survival benefit with hyperthermia with hazard ratio of $0.66 .^{(91)}$

Hyperthermic isolated limb perfusion for treatment of extremity soft tissue sarcomas has been assessed in multiple phase II trials. In a recent meta-analysis of 518 patients across 12 studies, 408 had at least a partial response and 428 had the limb spared. Median complete and partial response rates were $31 \%$ and $55 \%$ respectively with limb sparing achieved for $83 \%$ of patients. While these results in total were encouraging, no trial fulfilled either all ideal or essential quality criteria and seven trials did not include statistical methodology. Therefore well designed prospective randomized trials are still warranted to validate these findings. ${ }^{(92)}$

\section{Bladder Cancer}

Combined hyperthermia and chemotherapy has also proven beneficial in treatment of non-muscle invasive bladder cancer. In a multicenter trial 83 patients with stage Ta and T1, grade G1 to G3 transitional cell carcinoma of the bladder were randomized to receive mitomycin $\mathrm{C}$ with or without 
radiation therapy following complete transurethral resection. Patients with low-risk disease were excluded. Patient and tumor characteristics were evenly matched. Freedom from tumor recurrence, the primary endpoint was significantly improved with addition of hyperthermia to $83 \%$ as compared to $42 \%$ with mitomycin C alone. ${ }^{(93)}$ In a subsequent report of long-term results, this benefit was maintained with median follow-up for tumor free patients of 91 months. 10 disease-free survival was $53 \%$ vs. $15 \%$ with vs. without hyperthermia. ${ }^{(94)}$

\section{Esophageal Cancer}

Researchers at Kyushu University in Japan performed a prospective randomized study exploring use of hyperthermia with chemotherapy in treatment of esophageal cancer. From January 1988 to June 1992, 66 patients with resectable squamous cell carcinoma of the thoracic esophagus underwent preoperative neoadjuvant therapy. 32 were treated with local hyperthermia combined with chemoradiotherapy and while 34 patients were treated with chemoradiotherapy alone. Over a three week period patients received $30 \mathrm{~Gy}$ in fifteen fractions combined with either bleomycin 30mg twice weekly or 150mg of cisplatin weekly with cisplatin being the primary chemotherapeutic agent from 1991 onwards. Patients randomized to hyperthermia received twice weekly treatments over the three week course. Patients proceeded to undergo a sub-total esophagectomy through a right thoracotomy with lymph node dissection 7-10 days after completion of neoadjuvant therapy. Patients characteristics were similar between groups with $63 \%$ and $65 \%$ having stage III or IV disease and $28 \%$ and $21 \%$ presenting with nodal disease in the hyperthermia plus chemoradiotherapy vs. radiotherapy alone groups. Radiation and chemotherapy received was also similar. "Markedly effective" pathologic response, as defined by established national guidelines was $25 \%$ and $6 \%$ and 3 year overall survival was $50 \%$ vs. $24 \%$ in the hyperthermia plus chemoradiotherapy and chemoradiotherapy alone groups respectively. ${ }^{(95)}$

\section{ADDITIONAL CLINICAL TRIALS}


In addition to the trials described above, non-randomized phase II and earlier trials have been done for these disease sites and others as well. While no randomized studies have been performed in prostate cancer to date, several trials have been reported. In a phase II trial from the Dana Farber Cancer Institute, addition of two trans-rectal ultrasound hyperthermia treatments to radiation and androgen deprivation was shown to be beneficial in treatment of locally advanced disease. 37 patients with clinical T2b, T2c, or T3 disease without seminal vesicle involvement were treated with then standard 66.6 Gy and a median of 6 months of androgen deprivation therapy. Median Gleason score and PSA were 7 and $13.3 \mathrm{ng} / \mathrm{ml}$. Patients treated on the short-term hormonal therapy arm of RTOG 92-02 were used as historical controls. The primary endpoint was absolute two year progression free survival. The addition of hyperthermia resulted in a significant increase in two year disease free survival of $84 \%$ as compared with $64 \%$ for the historical control group. ${ }^{(96)}$ With median follow-up of 70 months, 7 year survival was $94 \%$ with $61 \%$ remaining free of failure. No increase in long-term toxicity was noted. Other studies assessing use of various approaches to hyperthermia for prostate cancer have also yield interesting results however firm conclusions are difficult to draw due to heterogeneity of patients and treatment. ${ }^{(97-99)}$

Hyperthermic limb perfusion has been investigated in several non-randomized trials for melanoma, many with promising results. ${ }^{(100-102)} \quad$ These favorable findings lead the American College of Surgical Oncology Group to include hyperthermic limb perfusion as part of standard treatment in a phase III trial assessing melphalan with or without the addition of TNF- $\alpha$. As hyperthermia was used for all patients as part of the standard treatment administered to both groups, insight into the specific benefit of hyperthermia in this setting was not assessed in this phase III trial.

Whole body hyperthermia has been assessed in a limited number of phase I and II clinical studies. In a study of 37 patients with therapy resistant metastatic or advanced solid malignancies patients 
underwent treatment cycles consisting of cisplatin on day one, followed by whole body hyperthermia and simultaneous gemcitabine 36 hours later; then a second dose of gemcitabine one week later; and daily IFN- alpha. The protocol was well tolerated and was associated with antitumor activity in patients with a variety of advanced metastatic solid tumors. Notably, tumor response occurred with the addition of hyperthermia despite treating malignancies that had progressed on the same chemotherapy drugs administered as standard treatment. In particular, good responses were observed in patients with highgrade neuroendocrine and pancreas cancers. ${ }^{(103)}$

\section{CHALLENGES TO CLINICAL IMPLEMENTATION}

Despite compelling biologic rationale and benefit demonstrated in a majority of clinical trials, the clinical implementation of hyperthermia has been hindered by several factors. Challenges have included logistical concerns, definition of thermal dose goals equating with outcomes, quality assurance, and limitations of technology to deliver adequate heat.

The ability to prescribe hyperthermia and easily deliver it has been a challenge. Compared to radiation dosing defined by physics and chemotherapy dosing defined by physiology, hyperthermia is dependent on both physics and physiology. The body has several mechanisms to dissipate heat. While thermal conduction and other mechanisms account for some heat dissipation, increase in blood perfusion during hyperthermia is the primary way in which heat is removed from the targeted area. Hyperthermia treatment is therefore more directly "hands on" as adjustments in magnitude and distribution of power are typically necessary during hyperthermia treatment in response to changes in perfusion. This required degree of monitoring coupled with duration of treatment typically in the range of one hour, at therapeutic temperature tempered initial widespread enthusiasm for hyperthermia. 
Quantification of thermal dose that equates with clinical outcomes has also been a challenge but one that has been acceptably if incompletely addressed. Thermal dosimetric parameters now have been defined from clinical trials. In particular the minimum temperatures achieved in tumor have been shown most consistently to correlate with clinical outcome. Preclinical research on hyperthermia revealed a breakpoint in rate of cell killing at $43^{\circ} \mathrm{C}$. For each degree Celsius above $43^{\circ} \mathrm{C}$ the time needed for an equivalent effect at $43^{\circ} \mathrm{C}$ is halved whereas for each degree Celsius below $43^{\circ} \mathrm{C}$ four times as much time in needed to achieve the same extent of cell kill. A thermal dose parameter was developed to account for both the relevance of minimum temperatures achieved and the differential rates of cell kill at various temperatures. ${ }^{(104)}$ This parameter, cumulative equivalent minutes at $43^{\circ} \mathrm{C}$ achieved by $90 \%$ of the measured temperate points in the targeted area or CEM43T90, has been shown in multiple studies to correlate with clinical outcome. ${ }^{(83-84,105-112)}$

The field of thermal dosimetry continues to evolve given that most treatment thermal profiles are based on modest samples of temperature points in the heated region. Non-invasive approaches to temperature measurement capable of monitoring hundreds or thousands of points in real time is now possible albeit not widely available. Magnetic resonance imaging can be utilized using a technique referred to as proton resonance frequency shift (PRF) which uses the correlation of proton resonance in water with temperature to monitor heating non-invasively. ${ }^{(113)}$ Other techniques utilizing ultrasound or computed tomography are also being developed. Advances in non-invasive thermometry providing more complete thermal profiles promise to further understandings of clinically relevant thermal dose parameters.

The need for quality assurance guidelines became readily apparent with the conduction of early clinical trials. In response to challenges identified from these early clinical trials, leading organizations including the American College of Radiology, American Society for Therapeutic Radiation and Oncology and the 
Radiation Therapy Oncology Group (RTOG) published the first quality assurance guidelines in $1989 .{ }^{(14)}$ The authors of the report noted several problems including lack of standardization in equipment, treatment procedures, patient monitoring, and treatment documentation as available in radiotherapy. The paper presented several recommendations including a set of test procedures necessary to ensure proper operation of equipment, guidelines for frequency for such tests, and guidelines on quality control procedures to be used during treatment to improve the safety, effectiveness, and reproducibility of hyperthermia treatments. Furthermore examples of forms were presented to indicate the minimum data that must be collected for acceptable documentation of treatment. In three follow-up papers the RTOG published guidelines to address quality assurance issues pertaining to deep tissue. ${ }^{(115)}$ RTOG quality assurance guidelines for interstitial hyperthermia ${ }^{(116)}$ and ultrasound. $^{(117)}$ Recently, leading experts in the United States published a review of the competencies and tasks used in a hyperthermia clinic. Guidelines were provided for what the competencies specialist involved in delivery of care including physicians, physicists and technologists need to perform multiple tasks to ensure properly functioning equipment, appropriate patient selection, and to plan and administer hyperthermia treatment. ${ }^{(118)}$ The European Society for Hyperthermic Oncology has likewise published guidelines ${ }^{(119)}$ which were recently updated. Guidelines for the implementation of regional deep hyperthermia treatments under strict rules of quality assurance were provided. The guidelines were based on practical experience from several hyperthermia centers. Recommendations for hyperthermia treatments, including indication, preparation, treatment, and standardized analysis were presented. ${ }^{(120)}$

The technological challenge of delivery of effective hyperthermia was a primary concern early on. Over the past 35 years, several hundred devices and techniques have been developed for heating tissue. Technology for delivery of hyperthermia has come a long way from the clinical investigations of the 1980 's. Large improvements have been made in both thermal monitoring and power control for real 
time adjustment of heating distributions in the body. In many ways, advances in treatment planning and delivery for hyperthermia have paralleled advances in radiation therapy over this time.

Initially, clinicians attempted to treat tumors of widely varying size and location within the body using a limited set of fixed dimension "one size fits all" equipment that eventually proved to offer limited or no adjustability to accommodate individual tumor heating requirements. Equipment available for the initial clinical trials of hyperthermia used simple non-adjustable applicators that could effectively treat only volumes 3-4 cm diameter with excessive heating in the center of the field and rapid fall off at the edges. Second generation equipment began to appear in the 1990's with multi-aperture planar arrays and wellintegrated computer monitoring and control interfaces that provided improved thermal feedback. Basic treatment planning capabilities became available with 2-D generic tissue treatment planning to enable adjustment of heating patterns to fit a larger number of tumors. Over the past 10 years, the field has taken a significant leap forward. Several site-optimized applicators have been developed. These multielement phase and/or amplitude adjustable arrays are often combined with increasingly sophisticated treatment planning programs based on clinically realistic matching patient anatomic models. Improved real time thermal feedback is increasingly available. Techniques include use of mobile thermal mapping probes or non-invasive magnetic resonance image based volumetric temperature distribution monitoring during treatment.

\section{FUTURE DIRECTIONS}

Evolving areas of growth for hyperthermia include application of the principles of radio- and chemosensitization to thermal ablation, furthering the development of strategies for heat induced targeted drug delivery, definition of clinical strategies that take advantage of the tumor specific immune response that occurs with hyperthermia, and commercialization/distribution of new devices to enable treatment of a larger number of tumor sites. While thermal ablation is typically used alone, a heated 
but not ablated rim of tissue exists around the high temperature region which provides opportunity for enhanced tumor kill with radiation or chemotherapy. Moving forward from more complicated treatment approaches such as isolated limb perfusion, thermally sensitive liposomes and a range of nanoplatforms which facilitate release of encapsulated drug in a tightly defined temperature range are either under development or in some cases undergoing clinical investigation as methods to enhance chemotherapeutic effect. Thermally enhanced immunotherapy is a therapeutic strategy that awaits development. While there are several questions that need to be answered including timing, sequencing, and optimal dosing with immune therapies and radiation, the potential for hyperthermia to play a role in the rapidly growing field of oncologic immunotherapy is clear and warrants investigation. Lastly, continued advancement of technology akin to the advances in radiation planning, delivery, and monitoring are moving forward including more automated treatment delivery and comprehensive real time non-invasive thermometry.

\section{CONCLUSIONS}

The potential for hyperthermia to benefit cancer patients has long been recognized. New appreciation for the biologic and physiologic mechanisms through which hyperthermia may improve outcomes of radiation and chemotherapy treatments led to enthusiasm in the 1980's that subsequently waned due to technical limitations and the need to develop clinical standards for heat delivery. Despite these early challenges clinical trials for a wide range of malignancies have been completed with the vast majority indicating clinical benefit. Technology for heat delivery, standards for quality assurance and thermal biology have all significantly advanced in the 35 years since hyperthermia was introduced into the modern cancer clinic. Coupled with timely opportunities to advance multi-disciplinary cancer care 
through combination with state-of-the-art radiation, chemotherapy, and immunotherapy, renewed focus on hyperthermia in oncology is warranted by the broad cancer community. 


\section{References}

1. Aboelsoud, NH. Herbal Medicine in Ancient Egypt, Journal of Medicinal Plants Research, 4(2), 8286, 2010 Jan 18.

2. Ede A, Cormack LB. A History of Science in Society: From the Ancient Greeks to the Scientific Revolution, North York, Ontario, Canada: University of Toronto Press. (2012).

3. Jouanna J. Greek Medicine from Hippocrates to Galen: Selected Papers, Leiden, The Netherlands: 2012. Koninklijke Brill.

4. Mininberg DT. The Legacy of Ancient Egyptian Medicine. In J.P. Allen (Ed.). The Art of Medicine in Ancient Egypt, New York, Metropolitan Museum Press: 2005;13-15.

5. Nunn JF. Ancient Egyptian Medicine, Norman OK: London:British Museum Press, c1996. University of Oklahoma Press 1996.

6. Coley WB. The treatment of malignant tumors by repeated inoculations of erysipelas, with a report of ten original cases. Am J Med Sci. 1893;105:488-511.

7. Muller C. Eine neue Behandlungsmethode bosartiger. Geschwulste. 1910; 57:1490-1493.

8. Warren SL. Preliminary study of the effects of artificial fever upon hopeless tumor cases. Am J Roentgenol 1935; 33:75-87.

9. Dewey WC, Hopwood LE, Sapareto LA, Gerwedk LE. Cellular response to combinations of hyperthermia and radiation. Radiology. 1977 May;123:463- 474.

10. Westra A, Dewey WC. Variation in sensitivity to heat shock during the cell cycle of Chinese hamster cells in vitro. Int J Radiat Biol. 1971;19:467- 477.

11. Kim SH, Kim JH, Hahn EW. The Enhanced Killing of Irradiated HeLa Cells in synchronous culture by hyperthermia. Radiat Res. 1976 May;66(2):337-45.

12. Gerweck LE, Nygaard TG, Burlett M. Response of cells to hyperthermia under acute and chronic hypoxic conditions. Cancer Res. 1979; 9:966 -972.

13. Hahn GM, Shiu C. Adaptation to low pH modifies thermal and thermochemical responses of mammalian cells. International Journal of Hyperthermia. 1986;2:379 -387.

14. Henle KJ, Leeper DB. Combination of hyperthermia $\left(40^{\circ}, 45^{\circ} \mathrm{C}\right)$ with radiation. Radiology 1976;121:451- 454.

15. Kano E. Hyperthermia and drugs. In: Overgaard J, ed. Hyperthermic Oncology. London, Uk: Taylor \& Francis 1985;277-282.

16. Eddy HA. Alterations in tumor microvasculature during hyperthermia. Radiology. 1980;137:515521.

17. Song CW. Effect of local hyperthermia on blood flow and microenvironment: A Review. Cancer Res. 1984;44(suppl 10):S4721-S4730.

18. Kuwano H, Sumiyoshi K, Watanabe M, Sadanaga N, Nozoe T, Yasuda M. Preoperative hyperthermia combined with chemotherapy and irradiation for the treatment of patients with esophageal carcinoma. Tumori. 1995 Jan-Feb;81(1):18-22.

19. Dahl O. Interaction of heat and drugs in vitro and in vivo. In: Seegenschmiedt $M$, Fessenden $P$, Vernon C, editors. Thermoradiotherapy and thermochemotherapy. Vol. 1. Berlin: Springer Verlag; 1995;103-55.

20. Cividalli A, Cruciani G, Livdi E, Pasqualetti P, Tirindelli Danesi D. Hyperthermia enhances the response of paclitaxel and radiation in a mouse adenocarcinoma. Int $J$ Radiat Oncol Biol Phys. 1999;44:407-12.

21. Gabai VL, Zamulaeva IV, Mosin AF, Makarova YM, Mosina VA, Budagova KR, et al. Resistance of Ehrlich tumor cells to apoptosis can be due to accumulation of heat shock proteins. FEBS Lett. 1995 Nov 13;375(1-2):21-26. 
22. Gabai VL, Meriin AB, Yaglom JA, Volloch VZ, Sherman MY. Role of Hsp70 in regulation of stresskinase JNK: implications in apoptosis and aging. FEBS Lett. 1998;438:1-4.

23. Kampinga HH, Dikomey E. Hyperthermic radiosensitization: mode of action and clinical relevance. Int J Radiat Biol. 2001;77:399-408.

24. Mivechi NF, Dewey WC. DNA polymerase alpha and beta activities during the cell cycle and their role in heat radiosensitization in Chinese hamster ovary cells. Radiat Res. 1985;103:337-50.

25. Raaphorst GP, Ng CE, Yang DP. Thermal radiosensitization and repair inhibition in human melanoma cells: a comparison of survival and DNA double strand breaks. Int J Hyperthermia 1999; 15:17-27.

26. Raaphorst GP,Yang,DP, Ng CE. Effect of protracted mild hyperthermia on polymerase activity in a human melanoma cell line. Inter.J of Hyperthermia 1994;10:827-834

27. Vidair CA, Doxsey SJ, Dewey WC. Thermotolerant cells possess an enhanced capacity to repair heat-induced alterations to centrosome structure and function. J Cell Physiol. 1995;163:194-203.

28. Westra A, Dewey WC. Variation in sensitivity to heat shock during the cell cycle of Chinese hamster cells in vitro. Int J Radiat Biol. 1971;19:467-477.

29. Dewey WC, Diederich CJ, Dewhirst MW. Hyperthermia classic commentary: 'Arrhenius relationships from the molecule and cell to the clinic' by William Dewey, Int. J. Hyperthermia, 10:457-483, 1994. Erratum in Int J Hyperthermia. 2009 May;25(3):248.

30. Lepock JR, Frey HE, Ritchie KP. Protein denaturation in intact hepatocytes and isolated cellular organelles during heat shock. J Cell Biol. 1993 Sep;122(6):1267-76.

31. Lepock JR, Frey HE, Heynen ML, Senisterra GA, Warters RL. The nuclear matrix is a thermolabile cellular structure. Cell Stress Chaperones. 2001 Apr;6(2):136-47.

32. Lepock JR. Role of nuclear protein denaturation and aggregation in thermal radiosensitization. Int J Hyperthermia. 2004 Mar;20(2):115-30.

33. Roti Roti JL. Cellular responses to hyperthermia (40-46 degrees C): cell killing and molecular events. Int J Hyperthermia. 2008 Feb; 24(1):3-15.

34. Kampinga $\mathrm{HH}$, Dikomey E. Hyperthermic radiosensitization: mode of action and clinical relevance. Int J Radiat Biol. 2001 Apr;77(4):399-408.

35. Vidair CA, Dewey WC. Division-associated and division-independent hyperthermic cell death: comparison with other cytotoxic agents. Int J Hyperthermia. 1991 Jan-Feb;7(1):51-60.

36. McRae DA, Esrick MA, Mueller SC. Non-invasive, in-vivo electrical impedance of EMT-6 tumours during hyperthermia: correlation with morphology and tumour-growth-delay. Int J Hyperthermia. 1997 Jan-Feb;13(1):1-20.

37. Sakaguchi Y, Stephens LC, Makino M, Kaneko T, Strebel FR, Danhauser LL, et al. Apoptosis in tumors and normal tissues induced by whole body hyperthermia in rats. Cancer Res. 1995 Nov 15;55(22):5459-64.

38. Alekseenko LL, Zemelko VI, Zenin VV, Pugovkina NA, Kozhukharova IV, Kovaleva ZV, et al. Heat shock induces apoptosis in human embryonic stem cells but a premature senescence phenotype in their differentiated progeny. Cell Cycle. 2012 Sep 1;11(17):3260-9. Epub 2012 Aug 16.

39. Chanel J, Maury E. Study of thermal shock on the blood proteins in the hog-fish and tench. J Physiol (Paris). 1961;53:291-292.

40. Li GC, Petersen NS, Mitchell HK. Induced thermal tolerance and heat shock protein synthesis in Chinese hamster ovary cells. Int J Radiat Oncol Biol Phys. 1982;8:63-67.

41. Berger EM and Woodward MP. Small heat shock proteins in Drosophila may confer thermal tolerance. Exp Cell Res. 1983;147:437-442.

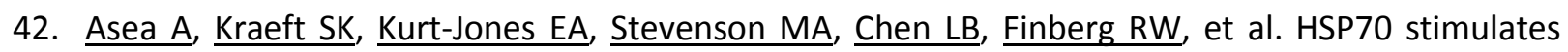


cytokine production through a CD14-dependant pathway, demonstrating its dual role as a chaperone and cytokine. Nat Med. 2000;6:435-442.

43. Srivastava PK, Maki RG. Stress-induced proteins in immune response to cancer. Curr Top Microbiol Immunol. 1991;167:109-123.

44. Udono H, Srivastava PK. Comparison of tumor-specific immunogenicities of stress induced proteins gp96, hsp90, and hsp70. J Immunol. 1994;152:5398-5403.

45. Udono H, Levy DL Srivastava PK. Cellular requirements for tumor-specific immunity elicited by heat shock proteins: tumor rejection antigen gp96 primes CD8_ T cells in vivo. Proc Natl Acad Sci USA. 1994;91:3077-3081.

46. Udono H, Srivastava PK. Heat shock protein 70-associated peptides elicit specific cancer immunity. J Exp Med. 1993;178:1391-1396.

47. Hurwitz MD, Kaur P, Nagaraja GM, Bausero MA, Manola J, Asea A. Radiation therapy induces circulating serum Hsp72 in patients with prostate cancer. Radiother Oncol. 2010;95:350-358.

48. Bull JM, Scott GL, Strebel FR, Nagle VL, Oliver D, Redwine M, et al. Fever-range whole-body thermal therapy combined with cisplatin, gemcitabine, and daily interferon-alpha: a description of a phase I-II protocol. Int J Hyperthermia. 2008 Dec;24(8):649-62.

49. Peer AJ, Grimm MJ, Zynda ER, Repasky EA. Diverse immune mechanisms may contribute to the survival benefit seen in cancer patients receiving hyperthermia. Immunol Res. 2010 Mar;46(13):137-54.

50. Repasky E, Issels R. Physiological consequences of hyperthermia: heat, heat shock proteins and the immune response. Int J Hyperther. 2002 Nov-Dec;18(6):486-9.

51. Coley WB. The treatment of malignant tumors by repeated inoculations of erysipelas: with a report of ten original cases. American Journal of Medical Science. 1893;105:486-511.

52. Pettigrew RT, Galt JM, Ludgate CM, Horn DN, Smith AN. Circulatory and biochemical effects of whole body hyperthermia. British Journal of Medicine. 1974;61:727-30.

53. Pomp H. Clinical application of hyperthermia in gynecological malignant tumors. In: Strefer C, editor. Cancer Therapy by Hyperthermia and Radiation. Baltimore, Munich: Urban and Schwarzenberg. 1978;326-7.

54. Robins HI, Dennis WH, Neville AJ, Shecterie LM, Marion PA, Grossman J, et al. A nontoxic system for $41.8^{\circ} \mathrm{C}$ whole-body hyperthermia: results of a phase I study using a radiant heat device. Cancer Research. 1985 Aug;45:3937-44.

55. Versteegh PMH, van Hoogen RHWM, Swaveling A. Systemic hyperthermia by the immersion bath method. Netherlands Journal of Surgery. 1981;33:195-9.

56. Wehner $\mathrm{H}$, von Ardenne A, Kaltofen S. Whole-body hyperthermia with water-filtered infrared radiation: technical-physical aspects and clinical experiences. Int J Hyperthermia. 2001 JanFeb;17(1):19-30.

57. Fujimoto S, Takahashi M, Mutou T, Kobayashi K, Toyosawa T. Successful intraperitoneal hyperthermic chemoperfusion for the prevention of postoperative peritoneal recurrence in patients with advanced gastric carcinoma. Cancer. 1999 Feb 1;85(3):529-34.

58. Parks LC, Minaberry D, Smith DP, Neely WA. Treatment of far-advanced bronchogenic carcinoma by extracorporeally induced systemic hyperthermia. Journal of Thoracic and Cardiovascular Surgery. 1979;78:883-92.

59. Olofsson R, Mattsson J, Lindner P. Long-term follow-up of 163 consecutive patients treated with isolated limb perfusion for in-transit metastases of malignant melanoma. Int J Hyperthermia. 2013 Sep;29(6):551-7.

60. Schwindenhammer B, Podleska LE, Kutritz A, Bauer S, Sheu SY, Taeger G, et al. The pathologic response of resected synovial sarcomas to hyperthermic isolated limb perfusion with melphalan 
and TNF-alpha: a comparison with the whole group of resected soft tissue sarcomas. World journal of surgical oncology. 2013;11(1):185.

61. Austin (Tx): Landes Bioscience; 2000. Madame Curie Bioscience Database (Internet).

62. De Simone M, Vaira M, Caponi A, Ciaccio B, Fiorentini G, Turrisi G, et al. Ten years' experience in the treatment of pseudomyxoma peritonei by cytoreduction, peritonectomy and semi-closed hyperthermic antiblastic peritoneal perfusion.In Vivo. 2006 Nov-Dec;20(6A):725-7.

63. Holzheimer RG, Mannick JA. Surgical Treatment: Evidence-Based and Problem-oriented. Editors Munich: Zuckschwerdt; 2001.

64. Polk HC Jr, Edwards MJ. Post-perfusion recurrent melanoma. Ann Surg Oncol. 1999 Sep;6(6):524

65. Johannsen $M$, Thiesen $B$, Wust $P$, Jordan $A$. Magnetic nanoparticle hyperthermia for prostate cancer. Epub. $2010 \mathrm{Jul}$ 23;26(8):790-5.

66. Ishihara K. Prostate Hyperthermia 2003-2004.

67. Chan KW, McDougall JA, Chou CK. FDTD simulations of Clini-Therm applicators on inhomogeneous planar tissue models. Int J Hyperther. 1995;11(6):809-20.

68. Chou CK, McDougall JA, Chan W, Luk KH. Effects of fat thickness on heating patterns of the microwave applicator MA-151 at 631 and 915 MHz. Int J Radiat Oncol. 1990;19(4):1067-70.

69. Sherar MD, Liu FF, Newcombe DJ, Cooper B, Levin W, Taylor WB, et al. Beam shaping for microwave waveguide hyperthermia applicators. Int J Radiat Oncol. 1993;25:849-57.

70. Straube WL, Myerson RJ, Emami B, Leybovich LB. SAR patterns of external $915 \mathrm{MHz}$ microwave applicators. Int J Hyperther. 1990;6(3):665-70.

71. Rietveld PJM, Van Putten WL, Van Der Zee J, Van Rhoon GC. Comparison of the clinical effectiveness of the $433 \mathrm{MHz}$ Lucite cone applicator with that of a conventional waveguide applicator in applications of superficial hyperthermia. Int J Radiat Oncol. 1999;43(3):681-7.

72. van Rhoon GC, Rietveld PJ, van der Zee J. A $433 \mathrm{MHz}$ Lucite cone waveguide applicator for superficial hyperthermia. Int J Hyperther. 1998 Jan-Feb;14(1):13-27.

73. Nikawa Y, Kikuchi M, Terakawa T, Matsuda T. Heating system with a lens applicator for $430 \mathrm{MHz}$ microwave hyperthermia. Int J Hyperther. 1990;6(3):671-84.

74. Nishimura Y, Hiraoka M, Mitsumori M, Okuno Y, Li YP, Masunaga S, et al. Thermoradiotherapy of superficial and subsurface tumours: analysis of thermal parameters and tumour response. Int J Hyperther. 1995;11(5):603-13.

75. Perez CA, Pajak T, Emami B, Hornback NB, Tupchong L, Rubin P. Randomized phase III study comparing irradiation and hyperthermia with irradiation alone in superficial measurable tumors. Final report by the Radiation Therapy Oncology Group. Am J Clin Oncol. 1991;14:133-141.

76. Emami B, Scott C, Perez CA, Asbell S, Swift P, Grigsby P, et al. Phase IIl study of interstitial thermoradiotherapy compared with interstitial radiotherapy alone in the treatment of recurrent or persistent human tumors. A prospectively controlled randomized study by the Radiation Therapy Group. Int J Radiat Oncol Biol Phys. 1996;34:1097-1104.

77. Sneed PK, Stauffer PR, McDermott MW, Diederich CJ, Lamborn KR, Prados MD, et al. Survival benefit of hyperthermia in a prospective randomized trial of brachytherapy boost +/hyperthermia for glioblastoma multiforme. Int J Radiat Oncol Biol Phys. 1998;40:287-295.

78. Datta NR, Bose AK, Kapoor HK, Gupta S. Head and neck cancers: results of thermoradiotherapy versus radiotherapy. Int J Hyperthermia. 1990;6: 479-86.

79. Valdagni R, Amichetti M. Report of long-term follow-up in a randomized trial comparing radiation therapy and radiation therapy plus hyperthermia to metastatic lymph nodes in stage IV head and neck patients. Int J Radiat Oncol Biol Phys. 1994;28:163-169.

80. Huilgol NG1, Gupta S, Sridhar CR. Hyperthermia with radiation in the treatment of locally 
advanced head and neck cancer: a report of randomized trial. J Cancer Res Ther. 2010 OctDec;6(4):492-6.

81. Mitsumori M, Zeng ZF, Oliynychenko P, Park JH, Choi IB, Tatsuzaki H, et al. Regional hyperthermia combined with radiotherapy for locally advanced non-small cell lung cancers: a multi-institutional prospective randomized trial of the International Atomic Energy Agency. Int J Clin Oncol. 2007 Jun;12(3):192-8. Epub. 2007 Jun 27.

82. Vernon CC, Hand JW, Field SB, Machin D, Whaley JB, van der Zee J, et al. Radiotherapy with or without hyperthermia in the treatment of superficial localized breast cancer: results from five randomized controlled trials. International Collaborative Hyperthermia Group. 1996 Jul 1;35(4):731-44.

83. Lepock JR. Cellular effects of hypertherthermia: Relevance to the minimum dose for thermal damage. Int J Hyperthermia. 2003 May-June;19:252-266.

84. Oleson JR, Samulski TV, Leopold KA, Clegg ST, Dewhirst MW, Dodge RK, George SL. Sensitivity of hyperthermia trial outcomes to temperature and time: Implications for thermal goals of treatment. Int J Radiat Oncol Biol Phys. 1993;25:289-297.

85. Jones EL, Oleson JR, Prosnitz LR, Samulski TV, Vujaskovic Z, Yu D, et al. Randomized trial of hyperthermia and radiation for superficial tumors. J Clin Oncol. 2005;23:3079-3085.

86. van der Zee J1, González González D, van Rhoon GC, van Dijk JD, van Putten WL, Hart AA. Comparison of radiotherapy alone with radiotherapy plus hyperthermia in locally advanced pelvic tumours: a prospective, randomised, multicentre trial. Dutch Deep Hyperthermia Group. Lancet. 2000 Apr 1;355(9210):1119-25.

87. Thomas GM. Concurrent chemotherapy and radiation for locally advanced cervical cancer: the new standard of care. Semin Radiat Oncol. 2000 Jan;10(1):44-50.

88. Lutgens L, van der Zee J, Pijls-Johannesma M, De Haas-Kock DF, Buijsen J, Mastrigt GA, et al. Review combined use of hyperthermia and radiation therapy for treating locally advanced cervix carcinoma. Cochrane Database Syst Rev. 2010 Mar 17;(3):CD006377. pub3. Review.

89. De Haas-Kock DF, Buijsen J, Pijls-Johannesma M, Lutgens L, Lammering G, van Mastrigt GA, et al. Concomitant hyperthermia and radiation therapy for treating locally advanced rectal cancer. Cochrane Database Syst Rev. 2009 Jul 8;(3):2009 Jul 8;(3):CD006269. pub2. Review.

90. Overgaard J. The current and potential role of hyperthermia in radiotherapy. International Journal of Radiation Oncology, Biology \& Physics. 1989;16:535-549.

91. Issels RD, Schlemmer M. Current trials and new aspects in soft tissue sarcoma of adults. Cancer Chemotherapy \& Pharmacology. 2002;49 Suppl 1:S4-8.

92. Trabulsi NH, Patakfalvi L, Nassif MO, Turcotte RE, Nichols A, Meguerditchian AN. Hyperthermic isolated limb perfusion for extremity soft tissue sarcomas: systematic review of clinical efficacy and quality assessment of reported trials. J Surg Oncol. 2012 Dec;106(8):921-8. Epub 2012 Jul 17.

93. Colombo R, Da Pozzo LF, Salonia A, Rigatti P, Leib Z, Baniel J, et al. Multicentric study comparing intravesical chemotherapy alone and with local microwave hyperthermia for prophylaxis of recurrence of superficial transitional cell carcinoma. J Clin Oncol. 2003 Dec 1;21(23):4270-6. Epub Oct 27.

94. Colombo R1, Salonia A, Leib Z, Pavone-Macaluso M, Engelstein D. Long-term outcomes of a randomized controlled trial comparing thermochemotherapy with mitomycin-C alone as adjuvant treatment for non-muscle-invasive bladder cancer (NMIBC). BJU Int. 2011 Mar;107(6):912-8. Epub 2010 Oct 4

95. Kitamura K, Ishida M, Kimura Y, Saeki H, Maehara Y, Sugimachi K. Early report of correlation between the thermal dosage and the treatment effect of hyperthermia in combination with chemoradiotherapy for esophageal cancer patients. Hepatogastroenterology. 2002 Nov- 
Dec;49(48):1560-2.

96. Hurwitz MD, Hansen JL, Prokopios-Davos S, Manola J, Wang Q, Bornstein BA, et. al. Hyperthermia combined with radiation for the treatment of locally advanced prostate cancer: long-term results from Dana-Farber Cancer Institute study. 2011;94-153. Feb 1;117(3):510-6.

97. Deger S, Taymoorian K, Boehmer D, Schink T, Roigas J, Wille AH, et al. Thermoradio- therapy using interstitial self-regulating thermoseeds: anintermediate analysis of a phase II trial. Eur Urol. 2004;45: 574-580.

98. Tilly W, Gellermann J, Graf R, Hildebrandt B, Weissbach L, Budach V, et al. Regional hyperthermia in conjunction with definitive radiotherapy against recurrent or locally advanced prostate cancer T3 pNO MO. Strahlenther Onkol. 2005 Jan;181:35-41.

99. Maluta S, Dall'Oglio S, Romano M, Marciai N, Pioli F, Giri MG, et al. Conformal radiotherapy plus local hyperthermia in patients affected by locally advanced high risk prostate cancer: preliminary results of a prospective phase II study. Int J Hyperthermia. 2007 Aug;23:451-456.

100. Taber SW, Polk HC Jr. Mortality, major amputation rates, and leukopenia after isolated limb perfusion with phenylalanine mustard for the treatment of melanoma. Ann Surg Oncol. 1997 JulAug;4(5):440-5.

101. Brobeil A, Berman C, Cruse CW, De Conti R, Cantor A, Lyman GH, et al. Efficacy of hyperthermic isolated limb perfusion for extremity-confined recurrent melanoma. Ann Surg Oncol. 1998 Jun;5(4):376-83.

102. Krementz ET, Sutherland CM, Muchmore JH. Isolated hyperthermia chemotherapy perfusion for limb melanoma. Surg Clin North Am. 1996 Dec;76(6):1313-30.

103. Bull JM, Scott GL, Strebel FR, Nagle VL, Oliver D, Redwine M, Rowe RW, et al. Fever-range wholebody thermal therapy combined with cisplatin, gemcitabine, and daily interferon-alpha: a description of a phase I-II protocol. Int J Hyperthermia. 2008 Dec;24(8):649-62.

104. Sapareto SA, Dewey WC. Thermal dose determination in cancer therapy. International Journal of Radiation Oncology, Biology \& Physics 1984;10:787-800.

105. Jones EL, Oleson JR, Prosnitz LR, Samulski TV, Vujaskovic Z, Yu D, et al. Randomized trial of hyperthermia and radiation for superficial tumors. J Clin Oncol. 2005;23:3079-3085.

106. Oleson JR, Samulski TV, Leopold KA, Clegg ST, Dewhirst MW, Dodge RK, et al. Sensitivity of hyperthermia trial outcomes to temperature and time: implications for thermal goals of treatment. Int J Radiat Oncol Biol Phys. 1993;25:289-97.

107. Dewhirst MW, Sim DA. Utility of Thermal Dose as a Predictor of Tumor and Normal Tissue Responses to Combined Radiation and Hyperthermia. Cancer Research 1984;44 (Suppl);4772s4780.

108. Hand JW, Machin D, Vernon CC, Whaley JB. Analysis of thermal parameters obtained during phase III trials of hyperthermia as an adjunct to radiotherapy in the treatment of breast carcinoma. International Journal of Hyperthermia. 1997 Jul-Aug;13:343-364.

109. Sherar M, Liu FF, Pintilie M, Levin W, Hunt J, Hill R, et al. Relationship between thermal dose and outcome in thermoradiotherapy treatments for superficial recurrences of breast cancer: data from a phase III trial. International Journal of Radiation Oncology, Biology \& Physics. 1997;39:371-380.

110. Seegenschmiedt MH, Martus P, Fietkau R, Iro H, Brady LW, Sauer R. Multivariate analysis of prognostic parameters using interstitial thermoradiotherapy (IHT-IRT):tumor and treatment variables predict outcome. International Journal of Radiation Oncology, Biology \& Physics. 1994 Jul;29:1049-1063.

111. Issels RD, Schlemmer M. Current trials and new aspects in soft tissue sarcoma of adults. Cancer Chemotherapy \& Pharmacology. 2002;49 Suppl 1:S4-8. 
112. Kapp DS, Cox RS. Thermal treatment parameters are most predictive of outcome in patients with single tumor nodules per treatment field in recurrent adenocarcinoma of the breast. International Journal of Radiation Oncology, Biology \& Physics. 1995;33:887-899.

113. Gellermann J, Wlodarczyk W, Feussner A, Fahling H, Nadobny J, Hildebrandt B, et al. Methods and potentials of magnetic resonance imaging for monitoring radiofrequency hyperthermia in a hybrid system. Int J Hyperther. 2005 Sep;21(6):497-513.

114. Shrivastava P, Luk K, Oleson J, Dewhirst M, Pajak T, Paliwal B, et al. Hyperthermia quality assurance guidelines. Int J Radiat Oncol Biol Phys. 1989 Mar;16(3):571-87.

115. Sapozink MD, Corry PM, Kapp DS, Myerson RJ, Dewhirst MW, Emami B, et al. RTOG quality assurance guidelines for clinical trials using hyperthermia for deep-seated malignancy. Int J Radiat Oncol Biol Phys. 1991 May;20(5):1109-15.

116. Emami B, Stauffer P, Dewhirst MW, Prionas S, Ryan T, Corry P, et al. RTOG quality assurance guidelines for interstitial hyperthermia. Int J Radiat Oncol Biol Phys. 1991 May;20(5):1117-24.

117. Waterman FM, Dewhirst MW, Fessenden P, Samulski TV, Stauffer P, Emami B, et al. RTOG quality assurance guidelines for clinical trials using hyperthermia administered by ultrasound. Int J Radiat Oncol Biol Phys. 1991 May;20(5):1099-107.

118. Myerson RJ, Moros EG, Diederich CJ, Haemmerich D, Hurwitz MD, Hsu IC, et al. Components of a hyperthermia clinic: recommendations for staffing, equipment, and treatment monitoring. Int J Hyperthermia. 2014 Feb;30(1):1-5. 861520. Epub 2013 Dec 18.

119. Lagendijk JJ, Van Rhoon GC, Hornsleth SN, Wust P, De Leeuw AC, Schneider CJ, et al. ESHO quality assurance guidelines for regional hyperthermia. Int J Hyperthermia. 1998 Mar-Apr;14(2):125-33.

120. Bruggmoser G, Bauchowitz S, Canters R, Crezee H, Ehmann M, Gellermann J, et al. Quality assurance for clinical studies in regional deep hyperthermia. Strahlenther Onkol. 2011 Oct;187(10):605-10. Epub Sep 19. 